\title{
¿QUÉ SIGNIFICA EDUCAR A LA PRIMERA INFANCIA EN LA POSTMODERNIDAD? ${ }^{1}$
}

WHAT DOES EARLY CHILDHOOD EDUCATION MEAN IN POSTMODERNITY?

Por: Mery Luz Pacheco Bohórquez ${ }^{2}$

Mónica Patricia Borjas ${ }^{3}$

Recibido: 15 de abril de 2019 - Aprobado: 13 de octubre 2019

\begin{abstract}
"Toda actividad pedagógica requiere poseer previamente una concepción de educación, y que a su vez-con anterioridad a toda concepción educativa se debe poseer una Filosofía del mundo y de
\end{abstract} la vida"

Cubero y Romero (2008)

\section{RESUMEN}

Este ensayo surge en el marco del Doctorado en Educación de la Universidad del Norte, específicamente en el seno del proyecto de investigación titulado: "Integración de las artes plásticas y visuales como eje transversal al currículo de educación preescolar en una escuela pública en la ciudad de Cartagena"; producto de la reflexión del proceso de revisión del marco teórico y conceptual sobre los significados de infancia y educación. La concepción de infancia, así como la comprensión del por qué y para qué educar, se constituyen en preguntas básicas y trascendentales que fundamentan la apuesta metodológica y didáctica, la cual se inscribe en un modelo pedagógico determinado.

Palabras clave: Infancia, educación, educación de la primera infancia, métodos de enseñanza.

\section{ABSTRACT}

This essay is a result of the research project: "Integration of plastic and visual arts as a transversal axis to the preschool education curriculum in a public school in the city of Cartagena", performed at the Doctoral Program of the Universidad Del Norte, Colombia.

\footnotetext{
${ }^{1}$ Este ensayo de carácter reflexivo surgió en el marco del módulo de Sociología y Educación liderado por el profesor Daniel Aguilar en el contexto del Doctorado en Educación de la Universidad del Norte. Este espacio contribuyó a problematizar el sentido del porqué y para qué educar a partir de interrogantes sobre la construcción social de la escuela como mecanismo de poder.

${ }^{2}$ Estudiante de Doctorado en Educación de la Universidad del Norte. Magíster en Educación con énfasis en Cognición y Educación, Universidad del Norte. Licenciada en Educación Infantil, Universidad Pedagógica Nacional de Bogotá.

${ }^{3}$ Docente del Dpto. de Educación de la Universidad del Norte. Doctora en Educación, Diseño Curricular y Evaluación Educativa, Universidad de Valladolid. Especialista en Enseñanza de las Ciencias y Licenciada en Educación con énfasis en Biología y Química, Universidad del Atlántico.
} 
It is an output of the review/reflection process on the theoretical and conceptual framework meanings of childhood and education. The conception of childhood, as well as the understanding of why and for what to educate, are the basic and transcendental questions on which it is rooted the methodological and didactic bet of the research, which is part of a specific pedagogical model.

Keywords: Childhood, education, early childhood education, teaching methods.

\section{INTRODUCCIÓN}

Pensar en un modelo pedagógico alternativo en la primera infancia, implica repensar los métodos o estrategias didácticas con el fin de responder a los retos que plantea educar a la primera infancia en la postmodernidad ${ }^{4} \mathrm{y}$ aclaren el horizonte del por qué y para qué educar. Los discursos sobre infancia y educación requieren analizarse cada vez más desde perspectivas críticas y situadas en un contexto histórico y socio-cultural debido a que dichas concepciones permean directa o indirectamente las decisiones y acciones en la educación inicial y marcan pautas para la configuración de los escenarios educativos, los roles de los actores del proceso educativo, la relación con el conocimiento y las metodologías adoptadas. Referente a este punto Aguerrondo y Vaillant (2015) destacan que es urgente un cambio de modelo educativo en América Latina y el Caribe que ayude a un cambio estructural de lo que es la base de la educación en cuanto a sus ejes centrales como las pautas que los determinan. Consideran que los contenidos deben formularse desde el pensamiento complejo y no desde la linealidad; el aprendizaje necesita repensarse desde la cultura, con el fin de revisar los contextos de adquisición y evaluación; la enseñanza tiene que plantearse en términos de experiencias y no en la transmisión de contenidos, y los recursos tienen que repensarse desde el aprendizaje y no a partir de la enseñanza. Con respecto a las reglas consideran que se debe romper con la uniformidad y obedecer a la diversidad cultural, ofrecer escenarios y tiempos flexibles que podrían mediarse por las tecnologías y promover el trabajo colaborativo.

Sobre este panorama, no es un secreto que el proyecto educativo de la modernidad ha fracasado tal como lo plantea Vargas (2006) y Gervilla (2010) quienes coinciden en que la educación es un proyecto sin cumplir y por eso se ha convertido en una utopía, en un constructo alejado muchas veces de la realidad, por lo que se hace necesario volver a ella y analizarla desde el enfoque postmoderno. Es decir, se requiere analizar las implicaciones que tiene educar en una época en que el papel o rol central de la escuela como ente educador por excelencia se ha desdibujado en una sociedad caracterizada por la globalización y el avance de las TIC, en la cual cobran cada vez más fuerza los escenarios informales para el aprendizaje, la relatividad del conocimiento, la individualidad, la diversidad y la libertad de pensamiento. Al respecto el Banco Mundial (2017) señala que existe una crisis de aprendizaje a nivel mundial debido a que se ha enfocado a la escolarización y no al

\footnotetext{
${ }^{4}$ Gervilla (2010) define la postmodernidad como: deconstrucción, agotamiento, personalización, hedonismo, indeterminación, pluralismo, desvalorización, apertura, relativismo, nihilismo positivo, narcisismo, individualismo, etc. Tendencia a enaltecer la diversidad sobre la homogeneidad, la individualidad sobre lo universal, a la libertad desenfrenada sobre la razón.
} 
desarrollo de las competencias básicas y al cierre de brechas sociales.

En esta vía se pretende analizar las distintas tendencias sobre las concepciones de infancia y educación que sustentan la escuela y requieren ser analizados con el fin de dilucidar elementos claves a tener en cuenta en un futuro, a nivel del diseño curricular, la planeación de contenidos y experiencias, así como las motivaciones que se pueden generar en el niño/a a partir de sus intereses y las características del entorno, para identificar retos que impone educar en la postmodernidad.

\section{De una infancia "Sujeta a" a una infancia "Diversa"}

Martínez (2011), Amador (2012) y Didonet (2012), confluyen en que la infancia es una construcción social que se ha modelizado, objetivado o universalizado debido a imágenes de interacción que marcan los agentes sociales, entidades gubernamentales, los medios de comunicación o modelos educativos de países hegemónicos, quienes construyen un ideal de la infancia. Según estos autores, considerar la infancia desde una perspectiva de derechos en términos de un discurso global que pretende universalizar la infancia con el fin de estandarizar los procesos de atención integral en los diversos países del mundo, especialmente los que están en vías de desarrollo, puede conducir a miradas sesgadas sobre los diversos contextos en que se desarrolla la infancia y las formas de construir sus subjetividades. También Ancheta (2008) y Martínez y Ospina (2014) convergen en esta misma idea. La categoría infancia es una construcción social anclada a dinámicas de poder. En este sentido, la infancia es una representación social que no puede pensarse desde un modelo universal sin tener en cuenta la diversidad cultural. Estos autores plantean que la pretensión de universalizar la infancia trae como consecuencia pensar a los niños y niñas desde una perspectiva centrada en el adulto, tradicional y biopsicológica, como una etapa ideal para moldear y justificar los dispositivos de intervención de un gobierno particular. Significaría, según estos autores, desconocer que existen distintas infancias y por ende posibles subjetividades, así como las múltiples realidades que están asociadas a escenarios y modos de socialización los cuales se enmarcan en contextos históricos, sociales y culturales específicos.

Sobre este mismo tema, Ancheta (2008) expresa que pese al reconocimiento de los derechos humanos de los niños no se evidencia un compromiso global por garantizar una educación para todos. Además, critica el posicionamiento de esta perspectiva desde el acceso y la obligatoriedad, y no como una oportunidad para romper con las barreras de la inequidad y exclusión social. Esta autora destaca que es necesario estudiar la infancia como una categoría social más amplia desde los derechos humanos y no solo desde lo psicológico y lo pedagógico.

Duarte-Duarte (2013), Amador (2012), Gallego (2012) y García (2015) coinciden en que se debe reconocer el término infancia desde la pluralidad, es decir a partir de la diversidad que caracteriza sus maneras de recorrer la niñez y marca las condiciones de aprendizaje, así como las múltiples experiencias e interacciones que construyen sus subjetividades. Amador (2012) y Gallego (2012) 
manifiestan que es fundamental trascender la mirada homogénea y universal que plantea el concepto de infancia en la modernidad, la cual invisibiliza sus voces y significados.

No obstante, este discurso sobre las "infancias" ha desencadenado en el enfoque de atención diferencial $^{5}$ a la primera infancia y en la necesidad de caracterizar, individualizar y velar por el respeto de las identidades y subjetividades de los sujetos, producto de unas dinámicas sociales, que ponen al descubierto las debilidades en la constitución de las estructuras políticas y económicas con relación a la educación.

En esta vía, el enfoque de atención diferencial fundamentado en el movimiento de la educación para todos promueve la diversidad desde la inclusión de diferentes grupos poblacionales con diversidad funcional, desplazados por la violencia, comunidades étnicas, entre otras; situación que exige la aplicación de unas políticas y unas prácticas inclusivas, evidenciado por ejemplo en una adaptación de la infraestructura, un manejo especializado del docente, metodologías flexibles así como recursos multivariados, el Diseño Universal para el Aprendizaje (DUA), aspectos que se presentan en un estado incipiente en nuestra sociedad. A fin de proponer procesos educativos, orientados a la formación integral y plena de los niños y niñas se hace necesaria una reflexión alrededor del concepto de educación, lo cual trataremos de presentar a continuación.

\section{Tendencias sobre el concepto de educación y su influencia en la configuración de un modelo educativo}

Educación es un término que denota múltiples significados según el contexto de referencia a nivel histórico, político, económico, cultural y social. Esto lo confirma Touriñan (2013) cuando expresa que "el sentido de la educación está vinculado a la respuesta formativa que en cada momento cultural se le da a la condición humana individual, social, histórica y de especie" (p. 39). Luego de realizar una revisión bibliográfica sobre el concepto de educación se explican las dos principales tendencias identificadas:

\section{a) La educación desde una perspectiva como escolarización masiva con objetivos económi- cos y utilitaristas}

Calvo (2017) define la educación desde la perspectiva de escolarización masiva como una rutinización del proceso de enseñanza aprendizaje que genera relaciones artificiales y ortodoxas que cohíben el aprendizaje. Destaca que este tipo de educación está fundamentado en el deber ser, la norma y el control de tiempos, espacios, agrupación de niños por edades, proveer de contenidos específicos a los estudiantes y pocos espacios para la socialización, el libre pensamiento y la recreación.

\footnotetext{
5 "Método de análisis, actuación y evaluación, que toma en cuenta las diversidades e inequidades de la población en situación o en riesgo de desplazamiento, para brindar una atención integral, protección y garantía de derechos, que cualifique la respuesta institucional y comunitaria. Involucra las condiciones y posiciones de los/las distintos/as actores sociales como sujetos/as de derecho, desde una mirada de grupo socioeconómico, género, etnia e identidad cultural, y de las variables implícitas en el ciclo vital - niñez, juventud, adultez y vejez" (MINSALUD, 2013)
} 
Acosta (2012) y Calvo (2017) coinciden en que la escolarización es de origen eurocéntrico y está relacionado con la forma de concebir la educación en la modernidad y según el modelo económico capitalista y neoliberal. Para Acosta (2012) esta perspectiva, es una tecnología que se apoya en varios elementos: la utopía de enseñar a todos bajo el principio de igualdad social y el derecho a la educación; la alianza iglesia y Estado para dominar la educación; definición del niño desde el discurso pedagógico, psicológico y pediátrico, de acuerdo a su edad y desempeño estableciendo roles y diferenciaciones entre el enseñante y el aprendiz; resolver la necesidad de llevar la educación a las masas, enseñar a todos lo mismo al mismo tiempo; proveer un currículo nacional común para garantizar la homogeneidad de la identidad nacional donde el objetivo era dotar de herramientas básicas como la escritura; reglar la enseñanza a partir de tiempos y espacios asignados; la enseñanza bajo el enfoque de un método científico fundamentado en evaluaciones periódicas y promoción de un grado a otro a través de certificación; la lógica de una educación por niveles y propedéutica.

Así lo afirma Vargas (2017) cuando manifiesta que los discursos globales de entidades gubernamentales bajo el lema la educación para todos, enfocados hacia un aprendizaje a lo largo de la vida entre los años 60 y 90 han tomado como eje central la economía y la importancia de formar capital humano para el mercado laboral y no para el cambio social de las comunidades locales con el fin de responder a las sociedades industriales y postindustriales bajo el eslogan la sociedad del conocimiento. De aquí sobreviene el discurso sobre los beneficios de formar las competencias, la empleabilidad y la globalización. Esta situación ha puesto en tensión el verdadero sentido de la educación debido a que ha prevalecido el carácter instrumentalista promovido a nivel mundial con fines políticos y económicos, lo que ha generado fuerte reformas en las políticas educativas a nivel local. Según Sacristán (2013) una educación que asuma al sujeto como capital humano únicamente centrados en un oficio pierde su sentido original.

Este discurso ha permeado la educación inicial en Colombia, a partir de la adopción del discurso de las competencias a través del documento número 10, titulado: Desarrollo infantil y competencias en la primera infancia y el Instrumento diagnóstico de competencias básicas en transición; situación que ha incidido en la forma de asumir los desempeños de los niños a partir de competencias desde la primera infancia y la educación preescolar y por lo tanto de continuar perpetuando un modelo educativo basado en resultados, en unas evidencias y por lo tanto desde un enfoque económico. Si bien es cierto, este documento privilegia la promoción de los funcionamientos cognitivos como: identificación de emociones, elaboración del discurso, clasificación, entre otros; esos se articulan a la visión de competencias, cuyo fundamento epistemológico articulado a la educación infantil, aún se encuentra en discusión.

Esta visión de la educación plantea limitaciones a la hora de tomar decisiones pedagógicas y curriculares que afectan los ideales e intenciones formativas en la educación infantil: 
- Métodos de enseñanza aprendizajes enfocados en la instrucción y control de tiempos y espacios: Viniegra-Velázquez (2008, 2016, 2017), Freire (1978) y Calvo (2017) se refieren al carácter instructivo de la enseñanza mediado por el control de los tiempos, espacios y estandarización de contenidos, situación que genera homogeneización del sujeto, convirtiéndolos en ejercicios de adiestramiento que coartan el desarrollo natural, la creatividad y por ende la subjetividad. Al respecto Viniegra-Velázquez $(2016,2017)$, afirman que, desde tiempos remotos, la escuela se vio forzada a colocar el conocimiento y la información en el mismo peldaño de importancia favoreciendo así en los niños (a) actitudes sumisas, receptivas, pasivas, acumulativas, permisivas, acríticas y doctrinales con "verdades establecidas", en donde el conocimiento es sinónimo de consumo, acumulación y retención de información. Dichas actitudes que favorecen la indolencia, la crueldad, la indiferencia, la permisividad y la complicidad con y ante los excesos y abusos del poder manifiesto en el sometimiento a la dominación y el control. En esta posición, la escuela se coloca en contra de sus aspiraciones, expectativas e ideales haciéndola prácticamente irrelevante e indefensa ante las poderosas fuerzas subjetivas de la actualidad, y la condenan a perpetuar los atributos degradantes de las densas atmósferas sociales actuales (Viniegra-Velázquez, 2017).

Calvo (2017) destaca que la escolarización desdeña la subjetividad en ánimo de objetivizar al sujeto y al proceso de enseñanza aprendizaje, con el fin de medir y evaluar todo, olvidando que el aprendizaje es una condición inherente al ser humano y fluye de manera natural en contextos cotidianos y no requiere esfuerzos por condicionar espacios artificiosos, lineales, estrictos y a-históricos los cuales no promueven el libre pensamiento y expresión, situación que se relaciona con la naturaleza del cerebro y la auto-organización. Este autor, manifiesta que la creencia de que el aprendizaje solo se da en espacios organizados, poco flexibles, silenciosos y estáticos; desconoce que la auto organización se da gracias al caos. No obstante, aclara que no se puede favorecer una o la otra porque se afecta el proceso educativo en general. Para él resulta distinto hablar de educación que de escolarización. La primera se centra en las experiencias del ser humano mientras que la segunda se convierte en una práctica rutinaria de relaciones causales, previsibles y de imposición de normas. Por esta razón, según él, es necesario desescolarizar la escuela mas no eliminarla, a fin de brindar mayores espacios para la experimentación, la sensibilidad, el silencio, la meditación y el juego creativo.

- El educador como un "sujeto" y el educando como un "objeto": En este orden de consideraciones, Freire (1978) afirma que nos encontramos en una época de menosprecio de la humanidad por la humanidad, en donde las concepciones modernas de la educación no han logrado superar la concepción tradicional, denominada como "bancaria", la cual se refiere a la acentuación y no superación de la contradicción educador-educando, que 
contribuye a la domesticación del niño(a). Según este autor no se puede hablar de verdadera educación mientras el educador sea siempre el "sujeto" que tiene el conocimiento y el saber, sea quien eduque, discipline, hable, prescriba y defina contenidos, y el educando sea su "objeto" para educar porque no sabe y por tanto solo debe ceñirse a escuchar, obedecer, ser disciplinado, seguir la prescripción y no participar en la elección de contenidos. Para este autor, esta concepción de educación desfigura la condición humana del educando, convirtiéndolo en un depósito vacío que necesita ser llenado por trozos de mundos digeridos por otro, con cuyos residuos pretende crear contenidos de conciencia.

- Currículos homogeneizadores: Peralta (2007, 2014) coincide en que los currículos nacionales oficiales que se han aplicado en Iberoamérica han sido de carácter pre-modernista y modernista, por esta razón se caracterizan por ser homogéneos y estandarizados a pesar de manejar un discurso que reconoce al niño como sujeto en el proceso educativo. Como lo plantea Sacristán (2007): "Pues no será fácil mejorar la calidad de la enseñanza sino cambian los contenidos, procedimiento y contextos de realización de los currículos" (p. 10).

Según Viniegra-Velázquez (2016) la separación entre la experiencia vital y los contenidos del currículo, repercute en información carente de sentido para los educandos, al estar desconectado de sus realidades, necesidades e intereses, y explica por qué existen en estos sentimientos negativos referentes a la imagen de conocimiento que se han formado como resultado de sus experiencias escolares, y estos "saberes" no se perciben como un acto de creación personal, sino como algo extraño y ajeno a sus deseos, posibilidades e intereses, convirtiéndose en replicadores de las opiniones y productos de otros. Para este autor los currículos que no incluyen la experiencia vital del sujeto se caracterizan por presentar variedad de información monótona y desconectada que no les ayuda a los estudiantes a conocerse a sí mismos ni a las circunstancias que les rodean, a comprender a los demás y relacionarse con ellos de la mejor manera; a disfrutar de la vida y entender el mundo que le toca vivir y que, además, ante tal diversidad y "avalancha" de contenidos debe memorizar para repetirlos cuando se les requiera so pena de menosprecio, rechazo o exclusión.

Lo anterior, ha desencadenado sistemas educativos actuales que presumen de ser innovadores, progresistas, diferenciados y competentes, pero que en realidad son similares en cuanto al tipo de prácticas educativas que generan (Viniegra-Velázquez, 2016, 2017). Esto deriva en una formación donde el niño se convierte en un reproductor de conocimiento, un realizador de tareas o planas, por lo tanto, menoscaba su capacidad comprensiva, y su nivel de participación se puede tornar escaso y pasivo (De Zubiría, 2015).

De igual manera, formar desde una perspectiva de la homogeneización puede generar una 
formación fragmentada, irreflexiva, con limitados canales de expresión y poca creatividad, ya que se considera fundamental adiestrar a los niños, estos son fácilmente manipulables o influenciables por su contexto, motivados por fuerzas extrínsecas y no intrínsecas, orientados a la búsqueda de resultados inmediatistas (Flórez, 2005; Vasco, Martínez y Vasco, 2012; Pelegrino, 2015). En contraposición Pineda (2011) plantea que los sujetos no solo deben asumirse como consumidores de cultura sino como creadores y transformadores de la misma. En este proceso, juega un papel importante la edu-comunicación, es decir la incidencia de los medios masivos de comunicación y las tecnologías en las nuevas dinámicas relacionales con el conocimiento y los demás (Martín-Barbero, 2000). En este sentido los currículos deben pensarse desde un análisis de los contenidos de estos escenarios y su articulación con las necesidades y problemáticas del contexto educativo. Como lo expone Rafael Obregón, jefe de la Sección de Comunicación para el Desarrollo en el Fondo de las Naciones Unidas para la Infancia (UNICEF), la educación y el aprendizaje contemporáneo requieren pensar la vinculación de los medios masivos de comunicación a los programas curriculares, específicamente la televisión educativa (Universidad del Norte, 2018).

- Privación cultural: Sobre este tema Calvo (2017) destaca que la privación cultural deviene de la escolarización y por lo tanto restringe el acceso a las artes y las ciencias. Esta deprivación, señala el autor, puede afectar la posibilidad de decodificar los códigos que le permitan comprender la complejidad de su contexto lo que afectaría la posibilidad de apreciar detalles, ubicarse espacial y temporalmente en situaciones, discernir entre diferentes fuentes de información, identificar problemas, entre otras. En general Calvo (2017) afirma que la falta de experiencias de aprendizaje mediado genera la repetición de relaciones preestablecidas que coartan el aprendizaje, la creatividad, la participación educativa y democrática.

Frente a esta tendencia se plantean retos paradigmáticos que generen cambios estructurales en la educación y por ende la formación que se ofrece a los niños y niñas de nuestro país:

\section{b) Educación como práctica de libertad}

Von Zuben y Gallo (2012) y Molpeceres (2010) coinciden en que la educación desde esta mirada pretende analizar las estructuras ideológicas y sociales, el reconocimiento del sujeto como ser individual y social, con potencialidades, que se construye así mismo en interacción con el otro.

En esta misma vía se retoman los aportes de Freire (1978), Rodríguez Rojo (1997), Bárcena y Melich (2000) quienes se refieren a la educación como acontecimiento ético teniendo en cuenta la historia y la cultura que la cobija, ellos afirman que es necesario cuestionar la ciudadanía, la política, las artes y la cultura, y en general los acontecimientos históricos que atentan contra 
la dignidad humana. En esta medida estos autores destacan que es necesario trabajar sobre la pedagogía crítica en vez de promover una cultura tecnológica totalitaria que asume la educación con fines de fabricación fundamentada en el desarrollo de competencias, en el control, la programación y la evaluación. De igual manera, se destaca como sinónimos de la fabricación educativa la instrucción y el currículo como formas de planificar el proceso de enseñanza-aprendizaje de una manera sistemática y medible que es de carácter instrumental y por lo tanto se reduce a un resultado, a un producto. $\mathrm{Y}$ en ese sentido la educación se convierte en un medio, y por lo tanto conduce a la cosificación del sujeto, lo que puede generar violencia y totalitarismo.

De acuerdo a lo anteriormente planteado, la educación como acontecimiento ético significa formar la identidad de los sujetos desde la pedagogía de la esperanza, es decir del nacimiento y acogimiento del otro, y no desde las relaciones de poder. En esta medida cobran valor dos elementos: la educación de la memoria y la formación de la identidad. Desde este planteamiento la identidad se construye no solo desde la autonomía y la construcción de la subjetividad sino cuando se interpela la historia de sufrimiento del otro y se aplica la responsabilidad en la toma de decisiones. Esta concepción de educación como acontecimiento ético, destaca la importancia del uso de la literatura y las artes como estrategias para el rescate de la memoria histórica.

La propuesta de Freire (1978) alrededor de la educación como práctica de libertad, le confiere a la educación, un papel transformador a través de la praxis y la reflexión. Freire aboga por la democratización de la cultura, la democratización de la educación desde la cual las ideas se constituyen en generadoras de transformación auténtica tanto personal, como social. Freire, reclama la necesidad de promover espacios y tiempos para la concienciación del hombre y de las masas a través de la educación centrada en la autorreflexión sobre el mundo. Como afirmara Freire (1997: 64), "es la conciencia que tienen de ser seres inacabados lo que genera su educabilidad" y genera la esperanza, la capacidad de ser transformador.

Calvo (2017) se aproxima al concepto de educación como práctica de libertad desde la comprensión de la educación a partir de la teoría del caos y el orden. Expone que la educación consiste en un proceso relacional en la enseñanza aprendizaje, el cual debe estar mediado por espacios no estructurados que permitan el libre pensamiento y expresión con el fin de lograr la coherencia entre la teoría y la praxis. Este autor destaca que el orden sobreviene del caos y que éste es el principio universal que rige todas las cosas, el cual se caracteriza por la incertidumbre, el desequilibrio e irreversibilidad. Aclara que no se debe confundir caos con desorden o desobediencia a la norma sino en la necesidad de facilitar los procesos educativos y procurar un aprendizaje significativo, trascendental y creativo. Se trata de crear relaciones emergentes con una metodología que contemple contenidos abiertos, los cuales cuando se requiera den cabida a optar por alejarse de un marco lineal, ordenado, reversible y preciso. Por esta razón expone que el aprendizaje no se trata de responder preguntas sino de suscitar preguntas a partir del asombro en el estudiante con el fin 
de que construya sus propios conceptos y argumentos en la vida a partir de la experimentación. Calvo (2017) argumenta que los procesos creativos se caracterizan por ser caóticos y se desarrollan es espacios desestructurados e informales como por ejemplo el recreo.

Asegura que los niños deben tener un espacio libre para pensar y explorar a través de la lúdica y que esto contribuye a desarrollar su capacidad cognitiva, la participación y socialización. Desde esta perspectiva, la educación infantil ha de privilegiar espacios y experiencias donde al niño se le permita ser y disfrutar de su entorno, maravillarse frente a los pequeños detalles que la cotidianidad le brinda, jugar, explorar, preguntar, imaginar, crear, equivocarse y comunicarse. Experiencias en las cuales a través de las actividades rectoras: arte, literatura, juego, exploración del medio, se posibiliten interacciones consigo mismo, con los demás y con su medio para promover su propio conocimiento, reconocimiento, valoración y respeto.

\section{c) Educación desde una perspectiva artística.}

Touriñan $(2013,2015)$ define la educación desde una perspectiva artística a la que denomina ámbito de educación general a partir de la cual se promueve el sentido estético y la expresión artística. Este autor destaca que las artes se constituyen en un área de experiencia cultural como un eje central en la formación común y básica de todos los seres humanos porque promueve el desarrollo afectivo, los valores, la creatividad, la inteligencia, la toma de decisiones y en definitivas la creación del proyecto de vida. Este autor afirma que no se trata de enseñar los contenidos propios de las artes ni tampoco de formar a los niños para que sean artistas o profesionales sino de "educar con las artes". Esto implica darle valor al papel preponderante de la transversalidad del sentir estético. Las artes, se constituyen entonces en mediadoras para la construcción de significados a través de la contextualización histórica, política y cultural.

Tal como lo plantean Bruner (2000) y Flórez (2005): la educación está enlazada a la cultura. Bruner (2000) se centra en la interacción social y destaca que se debe promover en el sujeto la capacidad para usar recursos de construcción de significados y realidades. Flórez (2005) expresa que se trata de apropiarse del saber construido social y universalmente, autotransformarse y crear cultura. Articulado a esto, Vygotsky (2003) e Ivaldi (2014) coinciden en que las artes resultan ser un punto de partida y estrategia para preservar la cultura.

Vygotsky (2003) afirma que el arte está vinculado con la cultura, es base para el despliegue de la imaginación y esta a su vez es indispensable para la maduración del niño y la actividad creadora en cualquier ámbito, ya sea artístico, científico o técnico. Tal como lo plantea Llinás (2015): las artes y las ciencias están conectadas desde la propia naturaleza del hombre, lo que explica que la sensibilidad estética y las habilidades artísticas aparezcan antes de desarrollar las competencias comunicativas como lo señala Bamford (2009). 


\section{A manera de reflexión final}

La educación va articulada a la formación de los individuos, de la comunidad, de la sociedad. Esta es la función clave de la educación. Se trata como lo afirman Runge, Muñoz, \& Ospina (2015), de un proceso humano de constitución de sí. Este proceso, no puede darse en solitario. La educación solo es posible a través de la interacción humana y en los diferentes contextos y escenarios tanto formales, informales, como no formales (UNESCO, 2015). Si no hay interacción, resultaría imposible la comunicación de la cultura, fin central de la educación. Como lo afirma Amador (2007): en la educación emerge la cultura humana y es desde ella, desde las experiencias, visiones, proyectos, lenguajes, tiempos, es donde se afronta la formación humana (Schnitman, 1994).

Es clara la evolución que ha tenido el concepto de educación desde miradas tradicionales que se fundamentan en medidas exógenas, técnicas e instrumentalistas hacia perspectivas contemporáneas que se enfocan en el desarrollo pleno del ser humano visto de una manera integral.

Se podría afirmar que dichas conceptualizaciones evidencian que las diferentes posturas sobre educación responden a momentos históricos desde los cuales se instalan modelos económicos y políticos (Tawil y Congoureoux, 2013; UNESCO, 2015 y Vargas, 2017). Por esta razón, aunque se quiera avanzar hacia perspectivas alternativas, los modelos dominantes siguen imponiendo ciertas dinámicas relacionales entre los protagonistas del proceso educativo. Por ejemplo, el discurso sobre la educación sustentado en la escolarización y alfabetización implica una forma de asumir las interacciones, y las decisiones que se tomen al respecto permitirán cuestionar las instancias de control y poder las cuales empiezan a ser cuestionadas debido al poco progreso de las naciones y a las enormes brechas sociales (Banco Mundial, 2017; 2018).

En esta medida una educación alternativa, más allá de construir un ámbito superficial para proveer un proceso de enseñanza con estructura preestablecida, debe pensarse como un escenario dinámico, cambiante y cada vez más retador que sirva como plataforma que impacte el ser en la dinámica de la formación integral. Al respecto, Flórez y Vivas (2007) argumentan que el hombre no se humaniza por causa externa sino a partir del interior del sujeto, su lenguaje, su libertad de expresión, y el desarrollo de la razón y la sensibilidad a través de la interacción con la cultura, las artes, las ciencias y la filosofía. La formación es lo que queda, y los conocimientos, aprendizajes y habilidades son apenas medios para formarse como ser humano (Flórez y Vivas, 2007, p.167).

Por esta razón, una educación alternativa, y más especialmente en la educación infantil, plantea los siguientes retos:

- Frente a la distribución de tiempos y espacios rígidos, resignificar el sentido del espacio escolar a partir de un diálogo en comunidad, para transformar la mirada cuadriculada de la escuela y empezar a aprovechar y utilizar otros espacios vitales para la formación de los 
niños, como por ejemplo el recreo.

- Frente a la privación cultural, negociar con los padres de familias y entidades operadoras y/o administradoras la gestión de recursos humanos y económicos para trascender el espacio escolar y aprovechar la ciudad como escenario de aprendizaje que dota de identidad al sujeto.

- Frente al carácter instructivo de la enseñanza, posibilitar el cambio de roles entre niños y docentes, con el objetivo de mover del lugar de autoridad al docente para pensar otras dinámicas relacionales y metodologías invertidas que le den sentido a las vivencias y preguntas de los niños y permitan la emergencia de contenidos y experiencias con sentido.

- Frente a la perspectiva utilitarista de educación, recobrar el valor de la educación desde una perspectiva artística con el fin de recobrar la memoria histórica y la identidad cultural. - Frente a un sistema homogeneizador establecer metodologías didácticas y valorativas contextualizadas específicas, atendiendo a las necesidades del desarrollo de los niños y sus intereses.

- Frente a contenidos librescos y descontextualizados facilitar la experimentación y la emergencia de contenidos que surjan de las inquietudes del niño en relación con la cotidianidad.

- Frente a la influencia de los medios masivos de comunicación en los niños, articular sus contenidos al currículo y favorecer su uso desde una perspectiva crítica, ética y educativa.

Para terminar, es necesario recordar que el mayor reto de la educación debido a la influencia de los modelos políticos y económicos, es generar prácticas educativas alternativas que posibiliten la transformación de las políticas públicas a favor de la formación integral de la primera infancia.

\section{REFERENCIAS BIBLIOGRÁFICAS}

Acosta, F. M. (2012). Educar, enseñar, escolarizar: el problema de la especificación en el devenir de la pedagogía (y la transmisión). Tendencias pedagógicas. (20).pp.93-105. Recuperado de https:// dialnet.unirioja.es/servlet/articulo? codigo $=4105072$

Aguerrondo, I. y Vaillant, D. (2015). El aprendizaje bajo la lupa: Nuevas perspectivas para América Latina y el Caribe. República de Panamá, Panamá: UNICEF, documento oficial.

Amador Pineda, L. (2007). Formación en tiempos presentes hacia pedagogías emergentes. Revista Latinoamericana de Estudios Educativos (Colombia), 3 (1), 41-63.

Amador, J. C. (2012). Condición infantil contemporánea: Hacia una epistemología de las infancias. Pedagogía y Saberes, (37), pp. 73-87.

Ancheta, A. (2008). Hacia una concepción de la educación de la primera infancia como derecho: Avances y desafíos globales. Revista Iberoamericana de Educación, (47). pp. 1- 12. 
Banco Mundial (2017, septiembre 26). El Banco Mundial advierte sobre una "crisis del aprendizaje" en la educación a nivel mundial. Recuperado de: http://www.bancomundial.org/es/news/ press-release/2017/09/26/world-bank-warns-of-learning-crisis-in-global-education

Banco Mundial (2018). Informe sobre el desarrollo mundial 2018: Aprender para hacer realidad la promesa de la educación. Washinton, D.C.: World Bank Publications. [Extraído el 14 de octubre de 2017 de: https://openknowledge.worldbank.org/bitstream/handle/10986/28340/211096ovSP.PDF

Bamford, A. (2009). El factor ; Wuau!: El papel de las artes en la educación. Barcelona: Octaedro.

Bárcena y Melich (2000). La educación como acontecimiento ético. Paidós

Bruner, J. (2000). La educación puerta de la cultura, 3ra. ed. Madrid: VISOR DIS., S.A.

Calvo, C. (2017). Ingenuos, ignorantes, inocentes. Santiago, Chile. Ediciones de la Junji.

Cubero, L. y Romero, C. (2008). Pensar la educación. Conceptos y opciones fundamentales. Madrid: Pirámide.

De Zubiría, J. (2015). Los modelos pedagógicos. Hacia una pedagogía dialogante. Bogotá: Editorial Magisterio.

Didonet, V. (2012). Educación infantil en Perú y América Latina: Un desafío ante las múltiples infancias. Educación Vol. XXI, No. 40, p.p. 27-39.

Duarte-Duarte, J. (2013). Infancias contemporáneas, medios y autoridad. Revista Latinoamericana de Ciencias Sociales, Niñez y Juventud, 11(2). pp. 461-472.

Flórez, R. (2005). Pedagogía del conocimiento. 2da. ed. Bogotá, DC: Mc Graw Hill.

Flórez, R. y Vivas, M. (2007). La formación como principio y fin de la acción pedagógica. Revista Educación y Pedagogía, 19 (47). pp.165-173. Recuperado de: http://aprendeenlinea.udea.edu.co/ revistas/index.php/revistaeyp/article/view/6680/6122

Freire, P. (1978). La educación como práctica de la libertad. Siglo XXI. México

Freire, P. (1997). Pedagogía de la autonomía: Saberes necesarios a la práctica educativa. Paz y Tierra. Río de Janeiro.

Gallego, T. M. (2012). Familias, infancias y crianza: Tejiendo humanidad. Revista Virtual Universidad Católica del Norte, (35). pp. 63-82. 
García, D. L. (2015). Infancia múltiple en Colombia: Niñez en contextos de conflicto por recursos naturales. Revista Infancias e Imágenes, 4(2). pp. 127-136.

Gervilla E. (2010). Educar en la postmodernidad. Madrid: Editorial DYKINN, S.L

Ivaldi, E. (2014). Educación, arte y creatividad en las infancias del siglo XXI. En Sarlé, P., Ivaldi, E. y Hernández, L. (Coord.), Arte, educación y primera infancia: sentidos y experiencias (pp. 1128). Madrid: OEI.

Llinás. R. R. (2015, mayo 14). Rodolfo Llinás, 'Arte como construcción cerebral' [Archivo de video]. Recuperado de: https://www.youtube.com/watch?v=6nepe4C8Fs4

Martín-Barbero, J. (2000). Retos culturales: de la comunicación a la educación. Nueva Sociedad, 169. pp. 33-43.

Martínez, A. (2011). Unicef, dejad que los niños vengan a mí. Revista Educación y Pedagogía, 23 (60). pp. 45-65.

Martínez, J. E. y Ospina, N. (2014). Introducción. En J. E. Martínez y N. Ospina (Eds). Pensar las infancias: Realidades y utopías (pp. 7-12). Bogotá, DC: Pontificia Universidad Javeriana.

Molpeceres, A. (2010). Una teoría de la acción para la educación. Con-Ciencia Social, (14). pp. 15-29. Recuperado de https://dialnet.unirioja.es/descarga/articulo/3349175.pdf

Pelegrino, C. (2015). Una aproximación a la sistematización del concepto formación en la estructura teórica de la pedagogía. Varona, (61), págs., 1 - 18. Recuperado de: http://www.redalyc.org/ articulo.oa? $\mathrm{id}=360643422011$

Peralta, M. V. (2007). Primer informe: Estado del arte sobre pedagogía de la primera infancia (0 a 3 años) en Latinoamérica y Caribe (1), págs., 1 - 30. Recuperado de: http://www.oei.es/inicial/ articulos/estado_pedagogia_primer_infancia_0a3anos_ALyCaribe_peralta.pdf

Peralta, M. V. (2014). La construcción de currículos nacionales en educación infantil como parte de las políticas de calidad en Latinoamérica. RELAdEI, 3 (1). p.p. 63-72. Recuperado de http:// www.usc.es/revistas/index.php/reladei/article/view/4708/5064

Pineda, D. A. (2011). John Dewey. Selección de textos. (D. A. Pineda, Trans.). Medellín: Editorial Universidad de Antioquia. (Trabajo original publicado en 1961).

Rojo, M. R. (1997). Hacia una didáctica crítica. Editorial La Muralla. España. 
Runge, A. K., Muñoz, D.A., \& Ospina, C.A. (2015). Relaciones del saber sobre la educación y la formación (pedagogía) y del saber sobre lo humano (antropología) en Comenio, Rousseau y Kant: Aportes de la antropología pedagógica. Pedagogía y Saberes, (43), 9-28. DOI: http://dx.doi. org/10.17227/01212494.43pys9.28

Sacristán, G. (Comp.) (2013). En busca del sentido de la educación. Madrid, España: Ediciones Morata. Recuperado de http://ezproxy.uninorte.edu.co:2197/visor/24051

Schnitman, F. (1994). Nuevos paradigmas, cultura y subjetividad. “a. reimpresión 1998”. ed. Buenos Aires, Barcelona, México: Paidós.

Tawil, S. y Congoureoux, M. (2013). Una mirada actual a la educación encierra un tesoro. Evaluar la influencia del informe Delors de 1996.

Touriñan, J. M. (2013). Conocer, enseñar y educar no significan lo mismo. El carácter y sentido de la educación como referentes de su significado desde la mirada pedagógica. Teor. Educ. 25 (1). Págs., 25 - 46. Recuperado de: http://revistas.usal.es/index.php/1130-3743/article/view/11148/11572

Touriñan, J. M. (2015). Educación artística común, específica y especializada: Sustantivación y adjetivación de la relación artes-educación recuperado de http://dondestalaeducacion.com/_movil/ files/3014/7914/2801/68._Educ_artistic_curso_verano_Jul15_web_caste.pdf

UNESCO (2015). Replantear la educación. ¿Hacia un bien común mundial?

Universidad del Norte (2018, 03 de agosto). Medios, cognición, aprendizaje: Repaso de la evidencia y nuevas fronteras. Universidad del Norte. Recuperado de: https://www.uninorte.edu.co/web/ doctorado-en-educacion/noticias2? articleId=13707142\&groupId=495771

Vargas, G. (2006). Filosofía, pedagogía y tecnología. 3ra. ed. Bogotá, DC: Editorial Sociedad de San Pablo.

Vargas, C. (2017). El aprendizaje a lo largo de toda la vida desde una perspectiva de la justicia social, recuperado de http://unesdoc.unesco.org/images/0025/002500/250027s.pdf

Vasco, C., Martínez, A. y Vasco, E. (2012). Educación, pedagogía y didáctica: Una perspectiva epistemológica. En Hoyos, G. (2012). Filosofía de la Educación. Enciclopedia Iberoamericana de filosofía. (p. 110, Vol 29). Madrid: Editorial Trotta (edición digital pdf).

Vygotsky, L. (2003). La imaginación y el arte en la infancia. Madrid: Akal.

Viniegra, Velázquez L. (2008). Hacia un nuevo paradigma de la educación. Revista de Investigación 
Clínica, 60(4). Págs. 337-355. Recuperado de: http://www.medigraphic.com/pdfs/revinvcli/nn2008/nn084i.pdf

Viniegra-Velázquez, L (2016). Educación y proyecto vital en un mundo en colapso civilizatorio. Parte I. Investigación en Educación Médica, 5(19). pág.199-209. Recuperado de: http:// www.redalyc.org/pdf/3497/349746529009.pdf

Viniegra-Velázquez, L (2017). La educación en nuestro tiempo: ¿competencia o aptitud? El caso de la medicina. Parte I. Boletín Médico del Hospital Infantil de México, 74(2). pp.164 - 172. Recuperado de: https:/www.sciencedirect.com/science/article/pii/S1665114617300655

Von Zuben, N. y Gallo S. (2012). Filosofía, política y educación: Sobre la libertad. En Hoyos, G. (2012), Filosofía de la Educación. Enciclopedia Iberoamericana de Filosofía. (p. 196, Vol 29). Madrid: Editorial Trotta (edición digital pdf). 